\title{
Radiocarbon
}

1989

\section{RADIOCARBON DATA BASE: Q\&A-AN ARTIFICIAL INTELLIGENCE DATA FILE MANAGEMENT PROGRAM}

\author{
ROBERT M KALIN and AUSTIN LONG \\ Radiocarbon Dating Laboratory, Laboratory of Isotope Geochemistry \\ University of Arizona, Tucson, Arizona 87521
}

\begin{abstract}
The "C14" data base, designed and implemented at the University of Arizona Radiocarbon Dating Laboratory, uses Q\&A, an artificial intelligence data file management program. The data entered into this data base are easily retrievable and exportable for submission to RADIOCARBON, and to the International Radiocarbon Data Base (IRDB). The use of artificial intelligence allows both novice and experienced computer operators to search and retrieve data with few key strokes and normal English sentences.
\end{abstract}

\section{HARDWARE AND SOFTWARE}

The Radiocarbon Laboratory at the University of Arizona uses Q\&A, version 2.1 by Symantec Corporation, on an IBM-compatible AT computer with a 30 megabyte fixed disk. Q\&A can be used on any PC, XT or AT compatible with at least $512 \mathrm{~K}$ RAM, though a hard disk and fast clock speed are much more convenient.

Q\&A is a very simple and straightforward data file management system. The program is menu driven with function keys for important operations, such as the excellent HELP function. Q\&A incorporates the data base with a report-generation subsection, a quick and easy-to-use word processor (on which this paper was written), the artificial intelligence subsection, utilities, and the ability to run any outside program such as LOTUS 1-2-3. The word-processor module of Q\&A easily merges with information stored in the data base. Correspondence and bookkeeping forms can easily retrieve information in the data base for insertion in the text.

The computer knowledge needed to set up a data base with Q\&A is minimal. Our data base was created in full within two days of receipt of the program, and very few bugs needed to be "flushed out." Persons with no prior programming or database experience will find this program simple and flexible, and a relief from the complexities of other database programs.

Database forms within Q\&A can extend in length to 10 screen pages of 21 lines each and contain as many fields as will fit into this space. Q\&A has programming capabilities within the data base which are much simpler to use than those of other systems.

Reports or printouts from Q\&A can be routed to the screen for viewing, to serial or parallel ports or to an ASCII disk file. This ASCII data file can be written on the appropriate removable disk and transferred to other programs or to the IRDB. Information can be imported directly and easily to a Q\&A database file created from PFS:File, IBM Filing Assistant, 
University of Arizona, Radiocarbon Dating Lab, Information Sheet

Lab Number: $4755 \quad$ Date Received: 8 Apr 1987 Priority: Normal

Submitted by: Dr. C. Vance Haynes

Date Submitted: 8 Apr 1987

Affiliation: University of Arizona

Address: Dept. of Geosciences, Univ. of Ariz

City: Tucson State: Az Country: USA

Zip: 85721 Phone:

Collected by: C.v.Haynes

Affiliation: University of Arizona

Date Collected: 10 Feb 1986

Sample ID: 78A EG 86

Discipline Represented (use F1 for number): Archaeology

Field Packaging and Preservatives: Polyethylene ziplock bag

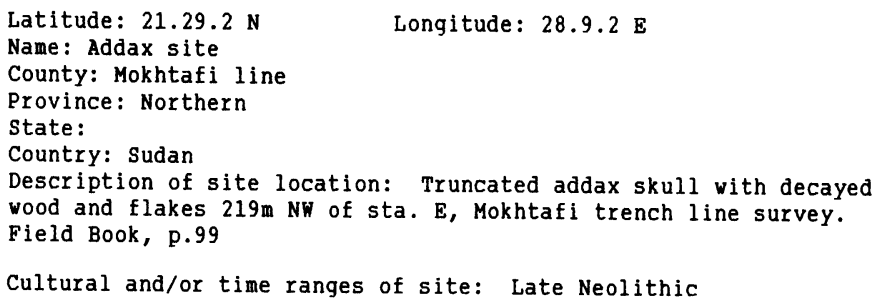

Cultural and/or time ranges of site: Late Neolithic

Previous dates from this site (stratigraphic position and reference):

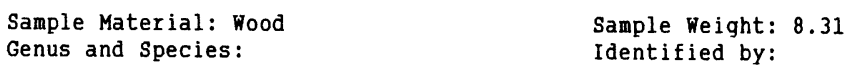

Further remarks on nature of sample and its matrix:

Depth below surface: Exposed in stage 2-3 sand sheet by wind Excavation Coordinates: $219 \mathrm{~m}$ NW of Sta. E, Mokhtafi line

Associated Cultural, paleontological or paleobotanical material: This site has hunting tools in association with an Addax kill.

Expected Age (what basis): $3000-5000$ BP (soil)

Importance of this date: The artifacts at this site point to late neolithic occupation of the area during a transition from pluvial to hyper arid climate.

Payment Arrangements :

Analysis by Gas Proportional: N Liquid Scintillation: Y Accelerator: N Completed by: $\mathrm{K}$. Katzer

Date: 9 Apr 1987

Special instructions Sample is uncarbonized wood fragments

Describe Pretreatment 3M $\mathrm{HCl} /$ rinse / $\mathrm{NaOH} /$ rinse / re-acidify / rinse to $\mathrm{pH}$ neutral.

Results of pretreatment (Humates, Rootlets, grain size, etc ): Humates approximately 608 of sample, extremely black, very slight effervescence,

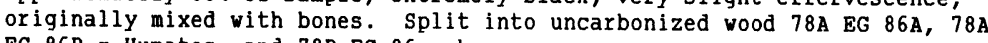
EG $86 \mathrm{~B}=$ Humates, and $78 \mathrm{~B}$ EG $86=$ bone.

By: R. Kalin

Dry weight before: 3.06

Ash veight after: 0.92

Volume $\mathrm{CO} 2$ gas: 2.8

$\begin{array}{ll}\text { Date: } 6 \text { May } 1987 & \text { By: N/A } \\ & \text { Carbonate weight: } 0.0 \\ & \text { Residue weight: } 0.0 \\ & \text { Volume c02 gas: } 0.0\end{array}$

Date: 
University of Arizona, Radiocarbon Dating Lab, Information Sheet

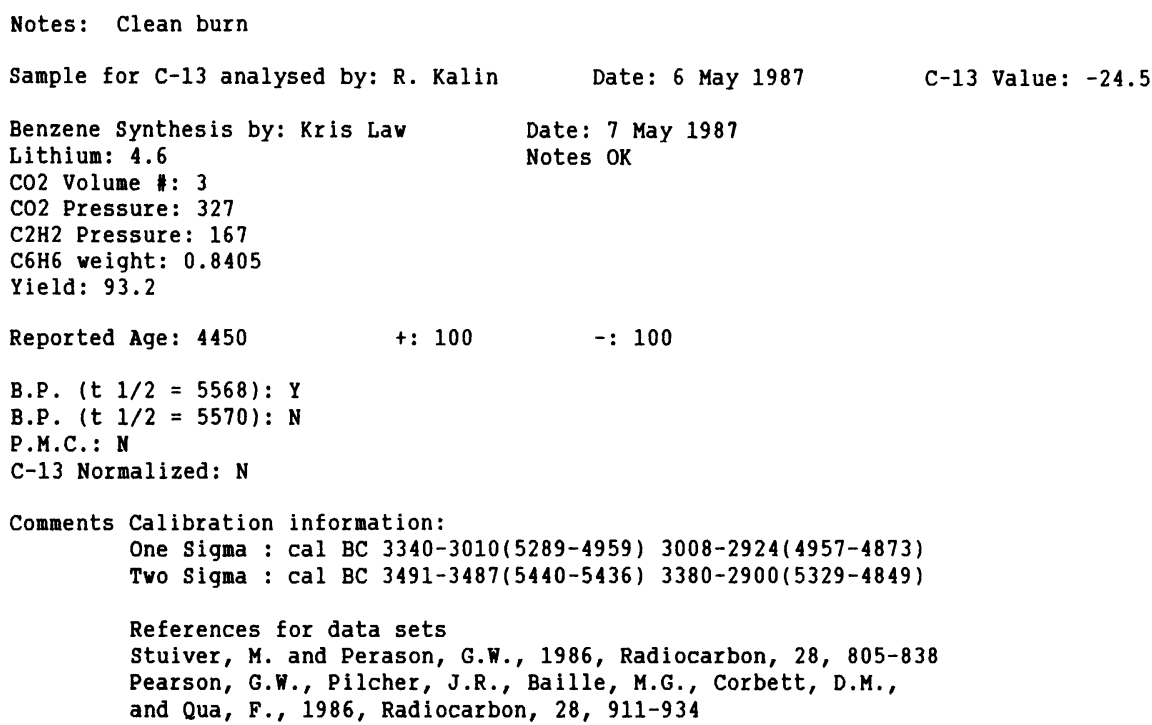

Fig 1. Sample provenience data information printed from database print specification which duplicates the original sample provenience sheet

LOTUS and Symphony, DIF format files, dBASE II and III, Fixed ASCII and Standard ASCII.

\section{STRUCTURE OF THE DATA BASE}

The database forms follow the entries found on the sample information sheet filled out for each sample submitted to the University of Arizona Radiocarbon Dating Laboratory (Fig 1). Information about each phase of pretreatment, combustion, benzene synthesis and counting is stored in the data base as well. Each form has 78 fields which comprise a total of 7 screens of information, easily scrolled through with cursor-pad control.

We have designed a series of print specifications for the data, which list the information selected, $i e$, sample types, sample disciplines, names and addresses, etc. Figure 2 shows a sample print specification for production of date lists for RADIOCARBON.

We have also designed a number of report specifications. A report differs from a print specification in that a report can print out any information in the data base to a form. The information to be reported can easily be sorted by any number of fields, and retrieved from any section of samples in the data base. Figure 3 shows part of a report that lists a log of the reported ages of samples submitted to our lab. A report will be written to print an ASCII file which contains sample information in IRDB format to transfer our lab information to the IRDB. 
University of Mrizona, Radiocarbon Date List

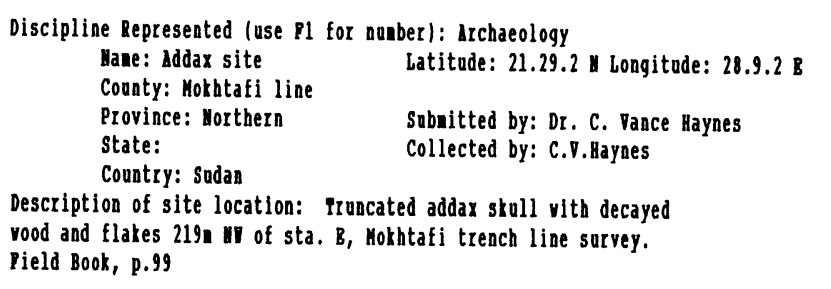
Lab Nunber: 1755
Sanple Material: Tood
Genus and Species:
c-13 Value: -21.5
Identified by:
Reported Ige: 1450
$t: 100 \quad-: 100$

Purther renarks on nature of sanple and its natrix:

Depth belov surface: Bxposed in stage 2-3 sand sheet by vind

Bxcavation Coordinates: 219n III of Sta. B, Mokhtafi line

Inportance of this date: The artifacts at this site point to late neolithic occupation of the area during a transition fron pluvial to hyper arid clinate.

issociated Cultural, paleontological or paleobotanical naterial: This site has hunting tools in association vith an addax kill.

Cultural and/or tine ranges of site: Late Neolithic

Pield Packaging and Preservatives: Polyethylene ziplock bag

Previous dates fron this site (stratigraphic position and reference):

Coments Calibration infornation:

One Signa : cal BC 3340-3010(5289-1959) 3008-2921(4957-4873)

Fvo signa : cal BC 3491-3487(5440-5436) 3380-2900(5329-1849)

References for data sets

Stuiver, H. and Perason, G.I., 1986, Radiocarbon, 28, 805-838

Pearson, G.I., Pilcher, J.R., Baille, M.G., Corbett, D.M.,

and Qua, P., 1986, Radiocarbon, 28, 911-931

Fig 2. Print specification of information which can be printed to a word-processing file for incorporation into date lists 
University of Arizona, Carbon-14 Laboratory, Log of Samples Analyzed

\begin{tabular}{|c|c|c|c|c|c|c|c|}
\hline Lab Nunber & Date Received & Subaitted by & Saaple Material & Reported Age & + & - & $c-13$ \\
\hline 3505 & 28 Jun 1983 & Robert H. Hebb & charcoal & 114.2 & 1.4 & 1.4 & -24.60 \\
\hline 3506 & 28 Jun 1983 & T. Van Devender & fecal pellets & 5860.0 & 60.0 & 60.0 & -24.00 \\
\hline 3507 & 28 Jun 1983 & T. Van Devender & fecal pellets & 5940.0 & 70.0 & 70.0 & -24.50 \\
\hline 3508 & 28 Jun 1983 & Ken Cole & pellets & 4800.0 & 80.0 & 80.0 & -23.90 \\
\hline 3510 & 23 Jun 1983 & Joel C. Janetski & plant fragnents & 1190.0 & 110.0 & 110.0 & -11.02 \\
\hline 3511 & 28 Jun 1983 & Joel C. Janetski & sandal frag & 1160.0 & 100.0 & 100.0 & -11.37 \\
\hline 3512 & 28 Jun 1983 & Martin Mead Agenbroad Davis & nood & 14730.0 & 320.0 & 320.0 & -26.50 \\
\hline 3513 & 28 Jun 1983 & Martin Mead Agenbroad Davis & charcoal & 5500.0 & 80.0 & 80.0 & -26.50 \\
\hline 3514 & 28 Jun 1983 & Martin Mead Agenbroad Davis & rood & 16700.0 & 250.0 & 250.0 & -25.40 \\
\hline 3515 & 28 Jun 1983 & Martin Mead Agenbroad Davis & dung & 11210.0 & 170.0 & 170.0 & -19.60 \\
\hline 3516 & 28 Jun 1983 & Martin Mead Agenbroad Davis & charcoal & 2640.0 & 50.0 & 50.0 & -26.00 \\
\hline 3517 & 28 Jun 1983 & T. R. Van Devender \& Martin & fecal pellets & 3820.0 & 70.0 & 70.0 & -23.60 \\
\hline 3518 & 13 Jun 1983 & Geocon Inc. & charcoal & 28200.0 & 1300.0 & 1300.0 & -24.80 \\
\hline 3519 & $13 \mathrm{Jul} 1983$ & Van Devender \& Tool in & other ? pellets & 2370.0 & 60.0 & 60.0 & -20.50 \\
\hline 3520 & 13 Jul 1983 & T. R. Van Devender \& Martin & turds & 8910.0 & 80.0 & 80.0 & -24.10 \\
\hline 3521 & $13 \mathrm{Jul} 1983$ & T. R. Van Devender \& Martin & turds & 7860.0 & 100.0 & 100.0 & -24.50 \\
\hline 3522 & 13 Jul 1983 & Lynn Teague & charcoal & 480.0 & 50.0 & 50.0 & -25.60 \\
\hline 3523 & $13 \mathrm{Jul} 1983$ & Lynn Teague & charcoal & 117.8 & 0.7 & 0.7 & -25.10 \\
\hline 3524 & 13 Jul 1983 & Lynn Teague & charcoal & 111.4 & 1.0 & 1.0 & -27.10 \\
\hline 3525 & $13 \mathrm{Jul} 1983$ & Lynn Teague & charcoal & 140.8 & 1.5 & 1.5 & -25.80 \\
\hline 3526 & $13 \mathrm{Jul} 1983$ & Lynn Teague & charcoal & 430.0 & 60.0 & 60.0 & -23.40 \\
\hline 3527 & 13 Jul 1983 & Lynn Teague & charcoal & 680.0 & 110.0 & 110.0 & -24.60 \\
\hline 3528 & 13 Jul 1983 & Lynn Teague & charcoal & 370.0 & 60.0 & 60.0 & -10.40 \\
\hline 3529 & 13 Jul 1983 & Lynn Teague & charcoal & 390.0 & 70.0 & 70.0 & -23.70 \\
\hline 3530 & $13 \mathrm{Jul} 1983$ & Lynn Teague & charcoal & 104.8 & 0.8 & 0.8 & -23.60 \\
\hline 3531 & 13 Jul 1983 & C.V. Haynes & charcoal & 7120.0 & 140.0 & 140.0 & -28.70 \\
\hline 3533 & $13 \mathrm{Jul} 1983$ & Glenn Roberts & vater & 12.6 & 0.8 & 0.8 & -12.80 \\
\hline 3534 & $13 \mathrm{Jul} 1983$ & Glenn Roberts & water & 43.0 & 0.8 & 0.8 & -13.00 \\
\hline 3535 & 19 Jul 1983 & T. R. Van Devender \& Martin & turds & 4010.0 & 70.0 & 70.0 & -24.10 \\
\hline
\end{tabular}

Fig 3. Printout of a summary of reported ages to be included in a lab log book, using the report-generation section 
Our database system also incorporates macros, which are series of stored keystrokes that are initiated with one keystroke. We have written macros to write form letters for billings, requests for more sample information and other frequent correspondence. A single keystroke will write out the letter, pausing for user entry of unique information, merge the letter with data stored in the data base, and print out the letter and envelope.

The most useful feature of Q\&A for the radiocarbon laboratory is the artificial intelligence (AI) module. To date, ca 2000 sheets of provenience information have been entered into one database file. Searching through the forms is simple with AI. For example, if we are interested in finding if any samples submitted by C Vance Haynes, Anthropology Department, University of Arizona, collected in the Sudan during 1986, had a reported age of $<10,000$ but $>3000$ years, the query entry to the artificial intelligence module would be as follows:

List samples submitted by C Vance Haynes, collected during the year 1986, which are younger than 10,000 years but greater than 3000 years.

The AI module would list a summary of the information we requested and create a report on the screen. This information can be printed out, or supplemental questions can be asked, such as:

Which of these were collected on 10 Feb 1986?

This ability to retrieve data quickly and in English sentence form makes our data base, designed with Q\&A, very helpful in the lab.

\section{CONCLUSION}

Q\&A, a powerful database program, is in use for storage and retrieval of radiocarbon information at the University of Arizona. This program is quite versatile and simple to use. The database system of $Q \& A$, including word processor, report generator, information import capabilities and artificial intelligence is a good choice for lab database use. Information stored in the Q\&A data base can be transferred to other systems and will transfer data for use in RADIOCARBON and the IRDB.

\section{ACKNOWLEDGMENTS}

The authors would like to thank Kristen Law, David Colbert and Deborah Kalin for their efforts in entering filing cabinets of information into this data base. We would also like to thank the Radiocarbon research group at the University of Arizona and C Vance Haynes for discussions and comments about the need and implementation of this database system.

Q\&A Manual, v 2.1, Symantec Corp.

\section{REFERENCE}

